\title{
Photocatalytic Oxidation of Triiodide in UVA-Exposed Dye-Sensitized Solar Cells
}

\author{
Matthew Carnie, Daniel Bryant, Trystan Watson, and David Worsley \\ SPECIFIC, College of Engineering, Swansea University, Baglan Bay Innovation Centre, Central Avenue, \\ Baglan Energy Park, Baglan, Port Talbot SA12 7AZ, UK \\ Correspondence should be addressed to David Worsley, d.a.worsley@swansea.ac.uk
}

Received 14 September 2011; Accepted 27 October 2011

Academic Editor: Jiaguo Yu

Copyright ( $\odot 2012$ Matthew Carnie et al. This is an open access article distributed under the Creative Commons Attribution License, which permits unrestricted use, distribution, and reproduction in any medium, provided the original work is properly cited.

UVA irradiation of glass mounted dye-sensitized solar cells without UV filtration causes failure within 400 hours of light exposure. The failure mode is shown to relate to consumption of $\mathrm{I}_{3}{ }^{-}$, which is directly related to $\mathrm{TiO}_{2}$ photo-catalysis. The onset of failure is easily determined from electrochemical impedance data where the recombination resistance of the $\mathrm{TiO}_{2} /$ electrolyte back reaction drops markedly prior to the onset of degradation. At the point of complete cell failure this impedance value then dramatically increases as there is no longer an interfacial reaction possible between the $\mathrm{TiO}_{2}$ and the $\mathrm{I}_{3}{ }^{-}$depleted electrolyte. Device failure is most rapid for cells under electrical load indicating that the degradation of the electrolyte is related to photogenerated hole production by excitation of the $\mathrm{TiO}_{2}$. Once depleted by $\mathrm{UV}$ exposure, the $\mathrm{I}_{3}{ }^{-}$can be regenerated by simple application of a reverse bias which can restore severely UV degraded devices to near original working conditions.

\section{Introduction}

As an alternative to conventional silicon solar cells, dyesensitized solar cells (DSCs) have been studied for some 20 years [1-3]. The photoelectrode most often used in DSCs is a nanoporous layer of $\mathrm{TiO}_{2}$ sintered onto a conductive glass or metal substrate. The photocatalytic properties of $\mathrm{TiO}_{2}$ are well documented [4-6], and photocatalytic reactions may proceed via several steps [7], the most important of which is the production of electron-hole pairs by direct excitation of the $\mathrm{TiO}_{2}$ with UV light. This results in a redox process, creating radicals which can ultimately result in degradative attack on organic molecules in the vicinity of the $\mathrm{TiO}_{2}$ [8]. Since both the DSC dye and the electrolyte have organic components, both are potentially susceptible to photocatalytic attack. It has been shown, however, that modification of the crystal structure and polarity of the $\mathrm{TiO}_{2}$ surface can impart photocatalytic selectivity leading to the possibility that one component could be degraded more favourably over the other $[9,10]$.

Some notable works have been published on DSC stability [11-19] as well as a comprehensive review published in 2010 [20]. The degradation of cells exposed to UV irradiation has been noted many times, as has a corresponding depletion in $\mathrm{I}_{3}{ }^{-}$from the electrolyte. Depletion of $\mathrm{I}_{3}{ }^{-}$has been observed in DSC cells subjected to outdoor testing as evidenced by an increase in the Nernst diffusion impedance and changes to the cell's Raman spectra [16], and it has been shown that in extreme cases decreased $\mathrm{I}_{3}{ }^{-}$concentration can cause a reduction in $J_{S C}$ by diffusion limitation [21]. The mechanism of $\mathrm{I}_{3}{ }^{-}$depletion has been suggested as either the sublimation of iodine [11] or perhaps the formation of iodate by reactions with water or other impurities in the electrolyte [22]. It appears, however, that $\mathrm{I}_{3}{ }^{-}$depletion could be as a result of a photoreactions as Sommeling et al. demonstrated that electrolyte bleaching occurred rapidly in illuminated cells held at $85^{\circ}$ but did not occur in cells held at $85^{\circ}$ and kept in the dark [13]. In DSCs, the photogenerated hole in the $\mathrm{TiO}_{2}$ valence band is said to be quenched by the iodide ion in the electrolyte [14]. However, DSC modules can degrade quickly under UV illumination [23], and the fact that filtering at $\lambda<384 \mathrm{~nm}$ improves the stability of a DSC cell [24] suggests that the photocatalytic properties of 
the $\mathrm{TiO}_{2}$ contribute at least in part to the degradation of the DSC.

A number of trends have been reported during longterm and accelerated tests. These include an increase in $J_{\mathrm{SC}}$ and a decrease in $V_{\mathrm{OC}}$ [18]. Electrochemical impedance spectroscopy (EIS) has also been used to monitor degradation, and it has been shown that the modelled resistance of the $\mathrm{TiO}_{2} /$ electrolyte back reaction decreases concurrently with the decrease in $V_{\mathrm{OC}}$ and that the drop in $V_{\mathrm{OC}}$ is due to a positive shift in the $\mathrm{TiO}_{2}$ conduction band [25]. This can also explain the increase in $J_{\mathrm{SC}}$, as a positive shift of the conduction band should increase electron injection efficiency [24]. The Nernst diffusion impedance of $\mathrm{I}_{3}{ }^{-}$has been shown to increase as a result of the change of the components of the electrolyte during long-term outdoor testing [16]. It was our primary aim with this work to examine the electrochemical and cell efficiency changes that occur in the early stages of DSCs exposed to UV light in order to determine whether failure was related to electrolyte or dye degradation and whether this resulted from photocatalysis. A key secondary goal was to determine if irradiation of cells under load or at open circuit had an effect since, in many cases, longevity testing is conducted in the latter condition. In order to achieve these aims, we have developed some rapid testing methods building on the electrochemical methods proposed by others $[13,14,18,25]$ and using a spectrophotometric method to determine degradation rates of dye and electrolyte in situ without the need for destruction of the cells. We have then used these systems to examine the effectiveness of some UV filtration and in terms of a potential method to revive cells that have been partially photodegraded.

\section{Experimental}

2.1. Cell Preparation. The photoanode was prepared by the doctor blading of a commercial $\mathrm{TiO}_{2}$ paste (DSL 18NRT (Dyesol)) onto Solaronix TCO22-15 fluorine-doped $\mathrm{SnO}_{2}$ glass followed by sintering at $500^{\circ} \mathrm{C}$ for 30 minutes giving a $7 \mu \mathrm{m}$ dry film thickness. The counter electrodes were prepared by the deposition of $5 \mathrm{mM}$ chloroplatinic acid and heat-treated at $400^{\circ} \mathrm{C}$ for 30 minutes. N719 dye was prepared at $0.3 \mathrm{mM}$ in a $1: 1$ acetonitrile/T-butanol solution. Adsorption of the dye to the $\mathrm{TiO}_{2}$ was achieved by immersion of the electrode in the dye solution over a period of 1620 hours. $50 \mu \mathrm{m}$ Surlyn gaskets were used to separate the electrodes and an electrolyte solution (0.8 M 1-propyl-3methylimidazolium iodide (PMII), $0.3 \mathrm{M}$ benzimidazole, $0.1 \mathrm{M} \mathrm{I}_{2}$, and $0.05 \mathrm{M}$ guanidinium thiocyanate dissolved in $\mathrm{N}$-methoxy propionitrile) was then introduced to the cell by vacuum injection. All test cells were made with a working electrode area of $1 \mathrm{~cm}^{2}$ except those cells used for UVVis measurements which had a working electrode area of $6.25 \mathrm{~cm}^{2}$, and the larger cells were needed in order to completely cover the sample aperture of the spectrophotometer.

2.2. Measurements. Photovoltaic characterisation was carried out using an Oriel Sol3A (94023A) utilizing a xenon arc lamp, an AM 1.5 filter, and a Keithley 2400 source meter. A reference measurement was provided using a monocrystalline silicon reference cell traceable to the National Renewable Energy Laboratory (NREL) that enabled adjustment of the solar simulator to the standard light intensity of one sun that is, $100 \mathrm{~mW} / \mathrm{cm}^{2}$.

Impedance spectroscopy measurements were carried out on a Solartron SI 1280 Electrochemical Measurement Unit using ZPlot software. Cells were measured in a two-electrode setup in the dark. All cell measurements in this study were conducted with a bias potential of $-0.68 \mathrm{~V}$, and the corresponding resistance values were averaged for the cell sets in question. AC amplitude was $\pm 10 \mathrm{mV}$ with a frequency range of $20 \mathrm{kHz}$ to $0.1 \mathrm{~Hz}$.

UV exposure was conducted using a custom-made bank of $6 \times 8$ W UVA lamps held $5 \mathrm{~cm}$ above the test cells. Measured intensity of the UV lamps was $0.64 \mathrm{Wm}^{-2}$ at a $\lambda_{\max }$ of $354 \mathrm{~nm}$. This is of comparable UV intensity to ASTM G173-03 (2008) which is given as $0.61 \mathrm{Wm}^{-2}$ at $354 \mathrm{~nm}$ [26].

\section{Results and Discussion}

3.1. Effect of UV Exposure upon Cell Efficiency. Exposure of unprotected DSCs to UV light induces failure which is illustrated in Figure 1 for identical cells forward illuminated and kept in the dark. After around 400 hours of exposure, the efficiency of the UV-exposed cells falls off dramatically whilst, in the dark, it is relatively constant. The change in efficiency, however, follows on from measurable electrochemical changes in the cell that occur well before the failure of the device as determined by its overall cell efficiency.

3.2. IV Measurements at 120-Hour Exposure. Figure 2 shows the typical $I-V$ curves of a cell at 0 -hour and 120-hour UV exposures for the cells illustrated in Figure 1. After just 120hour exposure, well before detectable changes in efficiency, it can be seen that $V_{\mathrm{OC}}$ decreases whilst $J_{\mathrm{SC}}$ increases. The change in $V_{\mathrm{OC}}$ has been attributed to UV exposure causing a positive shift in the $\mathrm{TiO}_{2}$ conduction band. This would explain the drop in $V_{\mathrm{OC}}$ as this is given by the energy difference of the $\mathrm{TiO}_{2}$ quasi-Fermi level and that of the redox potential of the electrolyte [27]. The increase in $J_{S C}$ due to UV illumination has been reported previously and has also been attributed to the positive shift in the conduction band [28].

3.3. EIS Measurements at 120-Hour Exposure. Figure 3 shows illustrative EIS Nyquist and Bode phase angle plots of the same cell type, again at 0 -hour and 120 -hour exposures. The larger semicircle of the Nyquist plot (Figure 3(a)) represents the impedance of the $\mathrm{TiO}_{2} /$ electrolyte back reaction $\left(R_{\mathrm{BR}}\right)$. It is clear from the Nyquist plot that the cell experiences a large decrease in $R_{\mathrm{BR}}$ whilst the decrease in the phase angle at lower frequencies shown in the Bode phase plot (Figure 3(b)) suggests that electron lifetimes in the $\mathrm{TiO}_{2}$ are reduced. Both of these results can be explained by an increase in the rate of the back reaction (1) [25]. This could arise from an initial exposure of the $\mathrm{TiO}_{2}$ surface, possibly by detachment of dye 


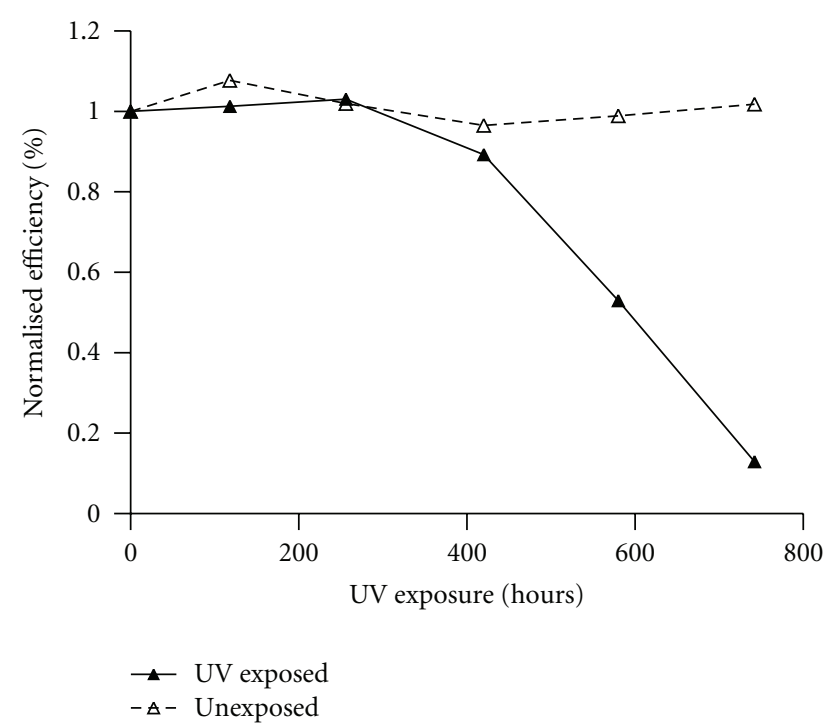

Figure 1: The effect of UV exposure on the $\% \eta$ of DSC test cells compared to that of cells kept in the dark (unexposed).

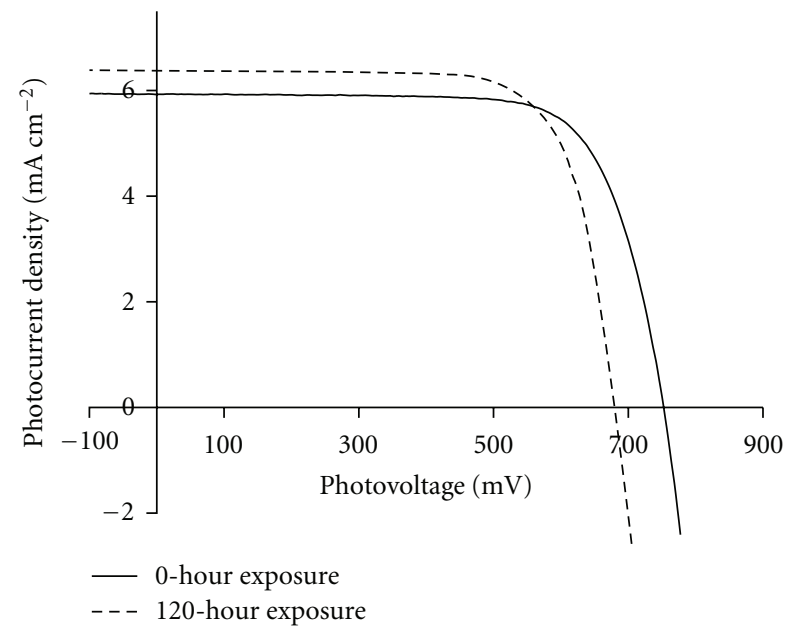

FIgURe 2: $I$ - $V$ curves of a typical cell at 0-hour and 120-hour UV exposures. It can be seen that $V_{\mathrm{OC}}$ has decreased, whilst $J_{\mathrm{SC}}$ has increased; however, as can be seen in Figure 1, there is no observable significant changes to cell efficiency.

ligands or by the initial removal of adsorbed organic species from the electrolyte

$$
\mathrm{e}^{-}\left[\mathrm{TiO}_{2}\right]+1 / 2 \mathrm{I}_{3}^{-} \longrightarrow 3 / 2 \mathrm{I}^{-} .
$$

3.4. Longer-Term Testing of Cells Irradiated in Reverse and under Load. Following these initial tests on forward illuminated cells, a more systematic study was performed on a wider range of conditions. Batches of 4 cells were irradiated from the WE (Forward) side, and, from the CE (Reverse) side, in addition, some were irradiated under a load provided by $100 \Omega$ resistor. These are compared to cells that were kept in the dark at $40^{\circ} \mathrm{C}$ as this was the measured temperature under the UV lamps. Figure 4 shows the mean efficiencies and the $V_{\mathrm{OC}}$ of the cells subjected to UV irradiation over

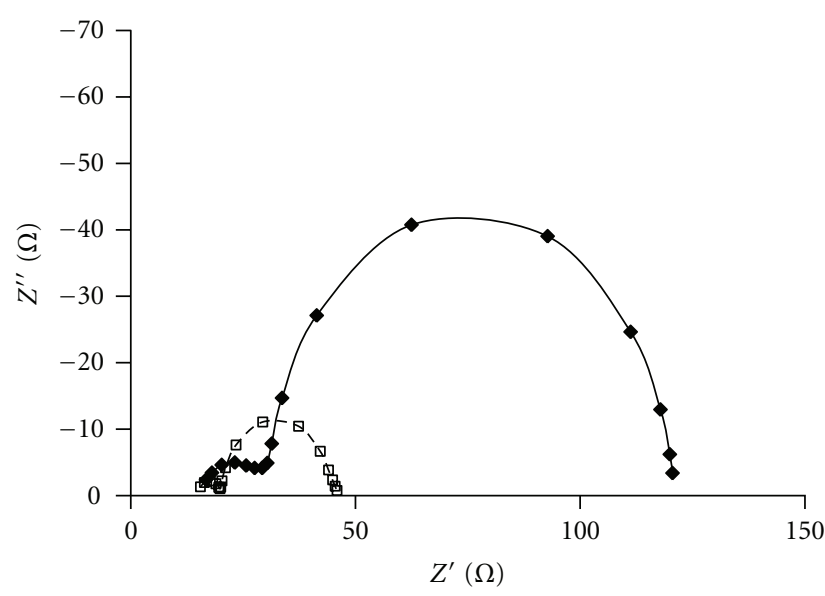

(a)

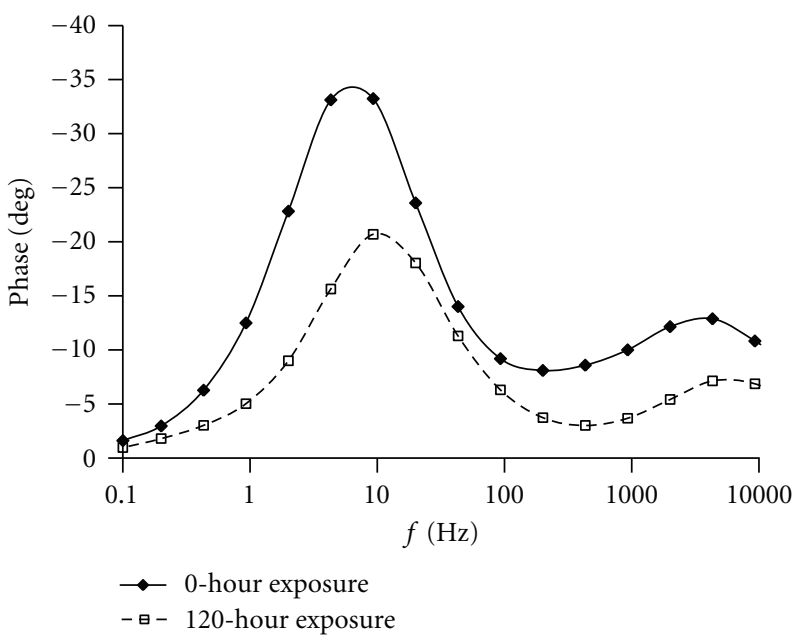

(b)

Figure 3: Nyquist plot (a) and Bode phase diagram (b) of the same cell as in Figure 2. These results are typical of all the cells exposed during this experiment.

the time period shown. In Figure 4, it is clear that there is a pattern in the relative rates of degradation of the cells tested. First to fail are the cells irradiated under load followed by cells irradiated from the WE side and then cells irradiated from the $\mathrm{CE}$ side. Cells kept in the dark at $40^{\circ} \mathrm{C}$ show comparatively little sign of degradation, despite a gradual decline in efficiency. This pattern is repeated when looking at the drop in $V_{\mathrm{OC}}$ values but, in this case, the drop in $V_{\mathrm{OC}}$ manifests itself much more quickly than the decline in efficiency. This data illustrates some important points. Firstly, the reverse illumination where photons travel through the electrolyte reduces photodegradation considerably as the electrolyte is acting as a filter. It does not, however, reduce the rate to zero. Secondly, the cells under load fail more quickly which suggests that the photogenerated electrons from the dye activation have a role to play in reducing the rate of failure when the cells are at open circuit.

Figure 5 shows the change in $J_{\mathrm{SC}}$ and the change in $R_{\mathrm{BR}}$ over the exposure period. The value of $R_{\mathrm{BR}}$ falls off 


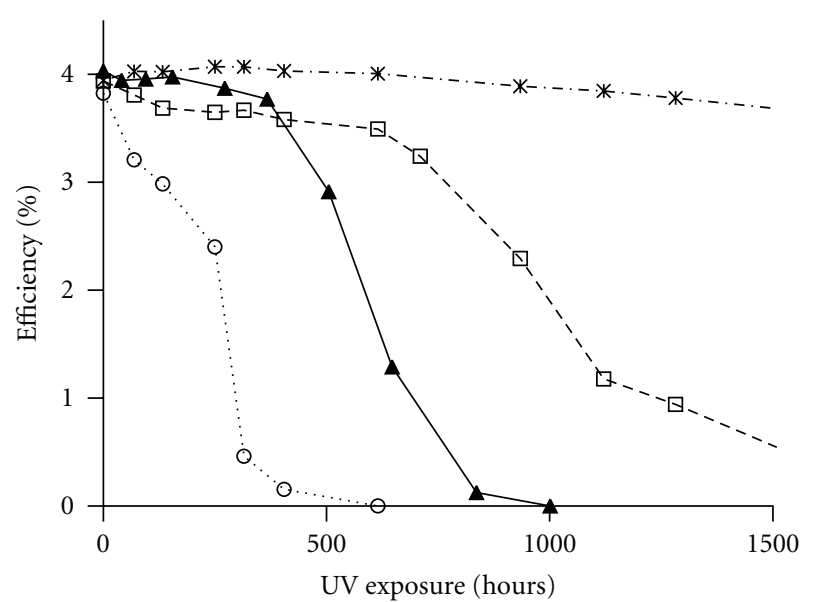

(a)

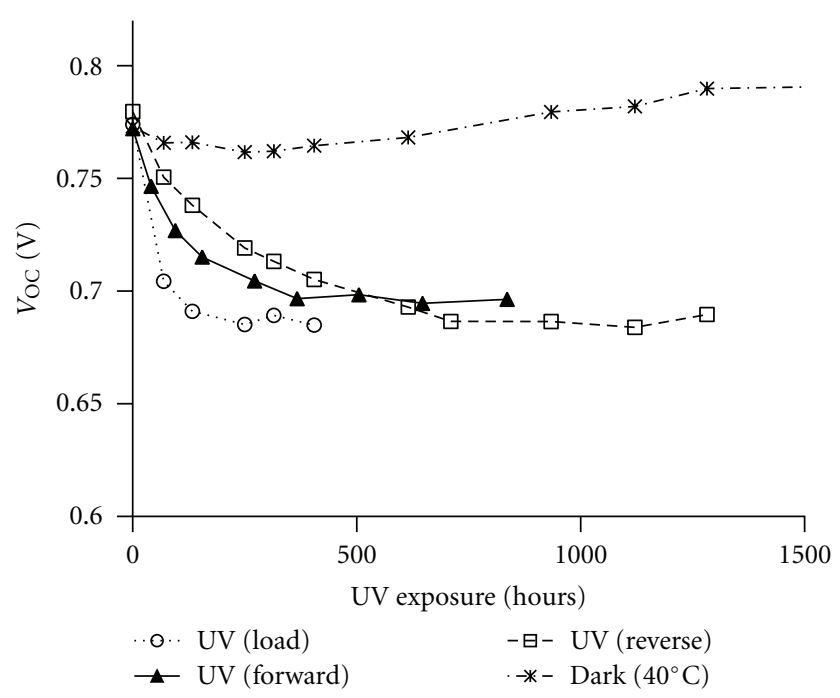

(b)

FIgURE 4: Change in (a) $\% \eta$ and in (b) $V_{\text {OC }}$ over the UV-exposure period. There is a clear order of cell degradation whereby cells under load and illuminated from the WE side fail before those under opencircuit (also illuminated from the WE side) which fail faster than those under opencircuit and illuminated from the CE side. Data is also shown for cells under opencircuit and kept in the dark for the exposure period.

quite quickly for all the cells suggesting that there is an increasing area of $\mathrm{TiO}_{2}$ in contact with the electrolyte after the initial UV exposure. Cells that are continually exposed to UV irradiation suffer a collapse in photocurrent and simultaneously a large increase in $R_{\mathrm{BR}}$. The onset of photodegradation also coincides with a loss of colour from the electrolyte which is measured by UV-Vis and is noticeable to the eye at the point of failure. This along with the collapse in $J_{\mathrm{SC}}$ and the large increase in $R_{\mathrm{BR}}$ strongly suggests that the cell degradation reaches a point where the $\mathrm{I}_{3}{ }^{-}$has been consumed until there are not enough charge carriers available to give the cell a viable photocurrent.

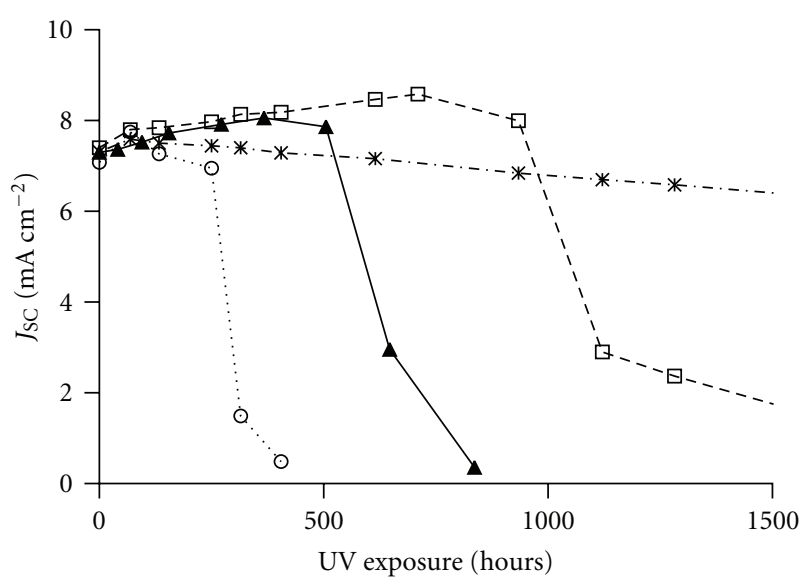

(a)

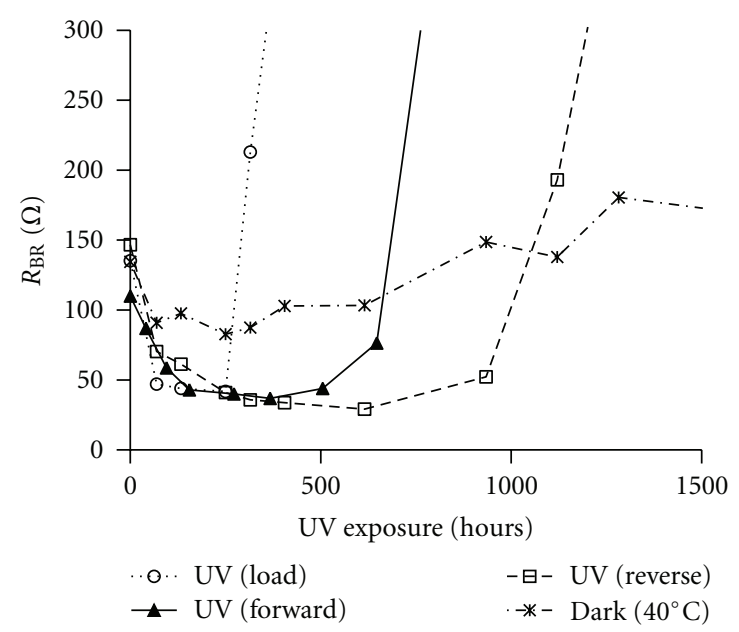

(b)

FIgure 5: Change in $J_{\mathrm{SC}}$ (a) and change in $R_{\mathrm{BR}}$ (b) over the UVexposure period, showing the collapse in photocurrent at the point of cell failure coinciding with a large increase in $R_{\mathrm{BR}}$. The order of cell failure is the same as in Figure 4.

3.5. Triiodide Depletion Measured with UV-Vis. UV-Vis spectroscopy is a useful method for analysing which of the components in the DSC is failing since both the dye and the electrolyte have absorbances which can be analysed simultaneously and in situ without taking the cells apart. The changing UV visible absorbance spectra for the forward illuminated cells are shown in Figure 6. It can be seen that the absorbance related to the adsorbed N719 dye (at ca $530 \mathrm{~nm}$ ) remains relatively constant and the main colour shift is at much lower wavelengths where the electrolyte is absorbing. This adds weight to the suggestion that it is the failure of the electrolyte that is responsible for the failure of the cells, despite the fact that it is the dye that is adsorbed on the $\mathrm{TiO}_{2}$.

This is more clearly illustrated in Figure 7 where the absorbance of the cell at $531 \mathrm{~nm}$ (the $\lambda_{\max }$ of the dye) and $450 \mathrm{~nm}$ (a representation of the electrolyte absorbance) is plotted as a function of time. $450 \mathrm{~nm}$ was chosen to represent dye colouration as the $\lambda_{\max }$ of the $\mathrm{I}^{-} / \mathrm{I}_{3}{ }^{-}$redox couple is hidden by the large absorbance of the $\mathrm{TiO}_{2}$. Figure 7 shows 


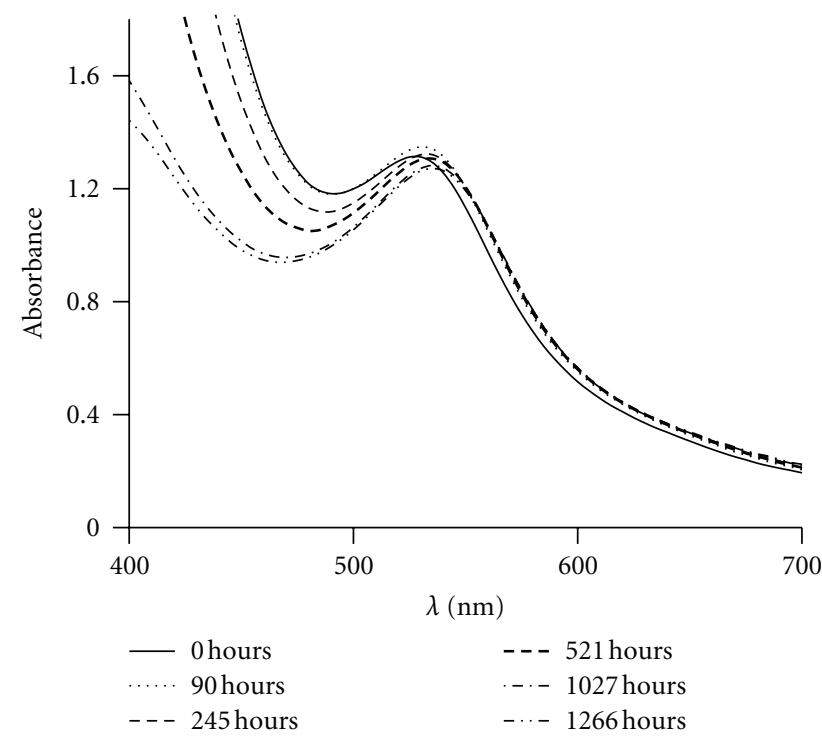

FIGURE 6: UV-Vis spectra of a typical cell over the exposure period shown.

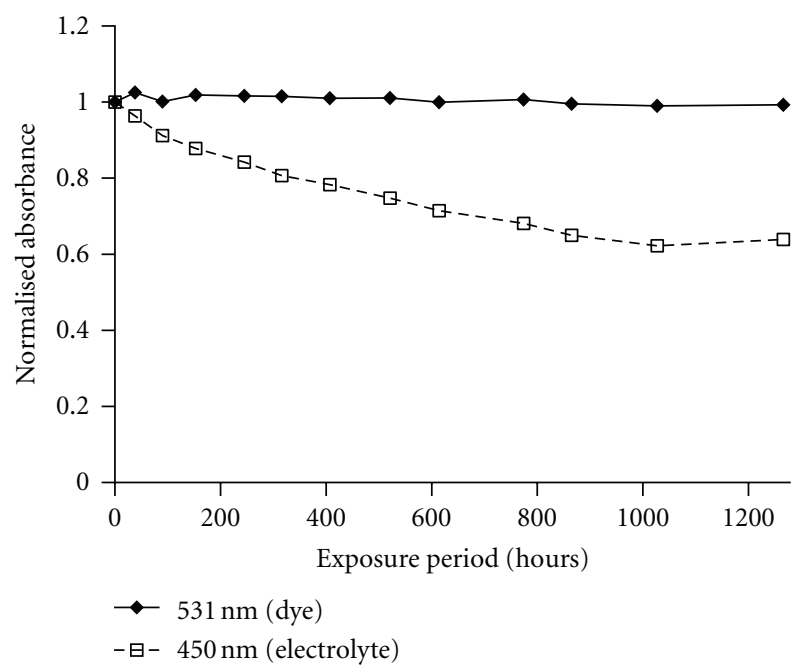

Figure 7: The changing absorbance of the cell at $531 \mathrm{~nm}$ (representing dye colouration) and at $450 \mathrm{~nm}$ (representing electrolyte colouration) of cells over the exposure period.

that the electrolyte is clearly being degraded whilst dye absorbance remains constant.

Having observed that the electrolyte was being degraded it was desirable to work out the origin of the failure. It could be that the electrolyte is directly attacked or that it is related to $\mathrm{TiO}_{2}$ photoreactions. Figure 8 illustrates the changes in electrolyte absorbance at $450 \mathrm{~nm}$ as a function of UV exposure time for two model cells. The first model cell was assembled from two counter electrodes (to examine whether UV alone caused the failure). The second cell type was essentially a full DSC assembly but without any dying step.

It can be seen from the data in Figure 8 below that the UV exposure alone does not cause failure but that having a

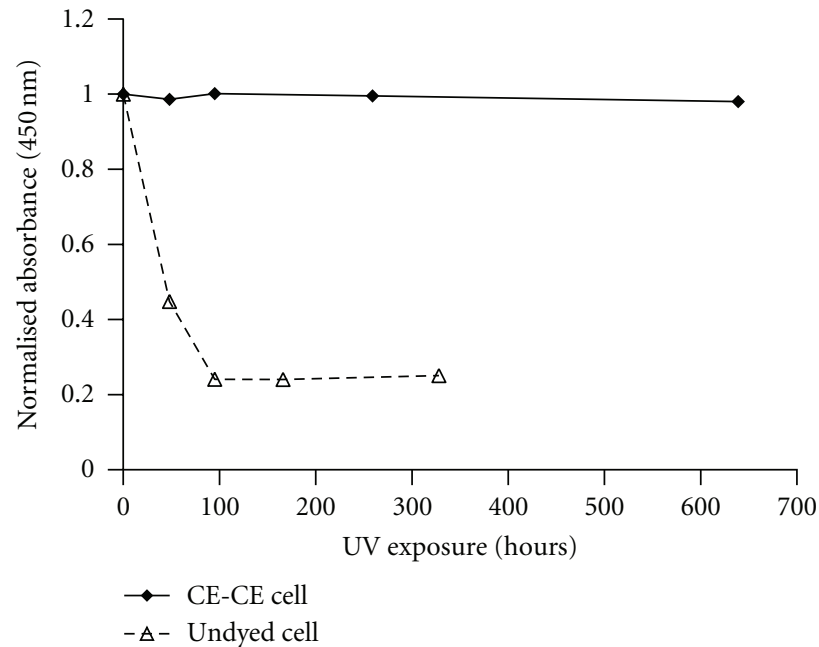

Figure 8: Change in absorbance of model cells. The undyed cell is essentially a complete DSC. The CE-CE cell consists of two counter electrodes and the electrolyte. This clearly shows that $\mathrm{TiO}_{2}$ is required for electrolyte degradation under UV illumination.

$\mathrm{TiO}_{2}$ electrode causes very rapid failure. There is almost no colour change in the $\mathrm{CE}-\mathrm{CE}$ cell, and it could be argued that the Pt is absorbing some of the UV light. Whilst this is true, it has been shown in Figure 5 that cells exposed via the CE side still degrade meaning that there is enough UV light reaching the $\mathrm{TiO}_{2}$ to initiate consumption of the $\mathrm{I}_{3}{ }^{-}$. If $\mathrm{TiO}_{2}$ was not involved in $\mathrm{I}_{3}{ }^{-}$consumption, then it would be expected that there might be a colour change in the $\mathrm{CE}-\mathrm{CE}$ cell despite the UV absorbing properties of the Pt layer.

Comparing the data in Figure 8 with that from Figure 7 where the dye is included on the $\mathrm{TiO}_{2}$, the presence of the dye dramatically slows the rate of cell failure. We believe this is for two reasons. Firstly, the dye will have taken up sites on the $\mathrm{TiO}_{2}$, and, secondly, it seems that at open circuit the dye is able to inject electrons into the $\mathrm{TiO}_{2}$ (as evidenced by the accelerated failure under load). Hence, it appears that it is the $\mathrm{TiO}_{2}$ and photooxidation by photogenerated holes that are the primary reason for attack on the electrolyte. Since it appears that photocatalytic oxidation could be responsible for the discoloration, the question remains what is the oxidised iodine containing species. At this stage, we have not been able to establish via chemical testing. One possibility for oxidation would be the reverse of (1), but this would of course give rise to a darker electrolyte. Since discolouration is observed, it therefore seems likely that the oxidation yields iodate as suggested in previous work [22]. Further work is in progress to assess; it is potentially the case that by drying and removing oxygen this pathway could be reduced although the $\mathrm{TiO}_{2}$ surface will still have a large quantity of surface bound hydroxyl groups that could lead to this.

3.6. UV Filtering. To investigate this further, a series of cells was irradiated with UV in the presence and absence of filters with certain wavelength cutoffs. The data shown earlier shows that $V_{\mathrm{OC}}$ changes are an early indicator of the 


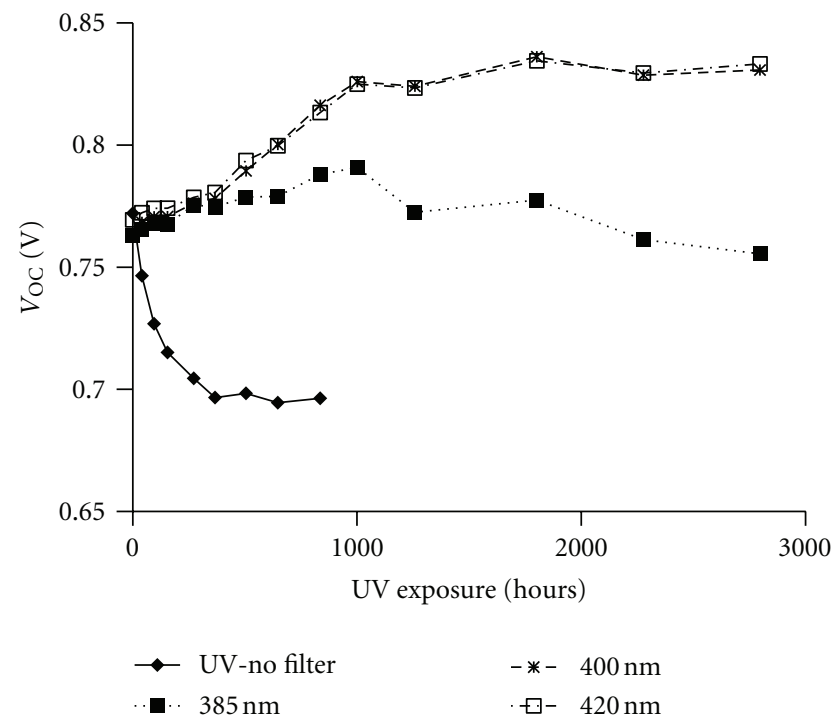

Figure 9: $V_{\text {OC }}$ data for cells filtered at $385 \mathrm{~nm}, 400 \mathrm{~nm}$, and $420 \mathrm{~nm}$ over the exposure period compared to cells exposed without a UV filter.

onset of cell degradation; for this reason, the change in $V_{\mathrm{OC}}$ was chosen as an indicator of the effectiveness of UV filters. $V_{\text {OC }}$ data for these cells is shown in Figure 9. The initial increase in the $V_{\mathrm{OC}}$ of all the filtered cells is typical of cells kept in the dark. It can be seen that the introduction of a $385 \mathrm{~nm}$ filter causes an initial increase in $V_{\mathrm{OC}}$, but, after some time, the $V_{\text {OC }}$ begins to decline indicating, albeit delayed, the onset of photodegradation. Using higher wavelength cut-off filters of 400 and $420 \mathrm{~nm}$ appears to stop this photooxidation completely (within our exposure times at least). This data again points to the potential for $\mathrm{TiO}_{2}$ photocatalysis to contribute to degradation since the $\mathrm{TiO}_{2}$ bandgap for direct excitation is in the range $360-380 \mathrm{~nm}$. The removal of this range of photons clearly prevents cell failure occurring rapidly.

3.7. Triiodide Regeneration by Application of a Reverse Bias. During the course of these investigations, it was found that UV-degraded and therefore $\mathrm{I}_{3}{ }^{-}$depleted cells can be regenerated by application of a reverse bias of around $+1.3 \mathrm{~V}$. Figure 10 shows the IV curves of the same cell before UV exposure, after UV exposure, and after electrolyte regeneration treatment. It can be seen that the cell, having undergone regeneration treatment, after a period of UV exposure, shows no significant recovery in $V_{\mathrm{OC}}$ but a partial recovery in $J_{\mathrm{SC}}$, with increase being attributed to the regeneration of $\mathrm{I}_{3}{ }^{-}$charge carriers in the electrolyte. The production of $\mathrm{I}_{3}{ }^{-}$via application of reverse bias has been noted before by Hauch and Georg [21], but it is not believed to have been reported in connection with the regeneration of UVdegraded DSCs. It was also found during these investigations that the less severely UV degraded the cell, the more effective the regeneration treatment is at recovering the cell to its original properties. It may be possible that by refining this treatment (in terms of the polarisation time, magnitude, and

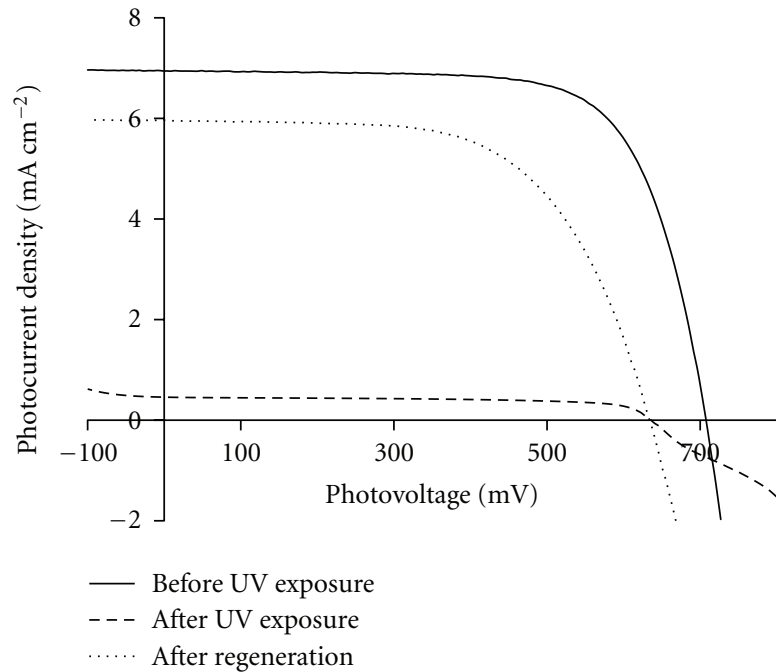

FIGURE 10: $I-V$ curves of a typical photodegraded DSC cell before UV exposure, after UV exposure, and after electrolyte regeneration treatment.

its frequency of application) the regeneration of the devices could be more effectively controlled. This is an attractive solution to restoring device performance since it could be periodically applied (e.g., at night) to maintain cell longevity.

\section{Conclusion}

Photocatalytic reactions instigated by UV irradiation are detrimental to dye-sensitized solar cell performance, and this study shows there are subtle changes that occur within a few days of exposure that manifest themselves before changes in cell efficiency are detected. The open circuit voltage, short circuit current, and back reaction resistance $\left(V_{\mathrm{OC}}, J_{\mathrm{SC}}\right.$, and $R_{\mathrm{BR}}$ ) all change relatively rapidly, and these are therefore potentially important indicators of cell degradation which can be to quickly evaluate UV protection measures, such as spectral cut-off filters. In addition, spectrophotometry is an important and simple tool for evaluating which component of the cell (dye or electrolyte) is under attack and enable kinetics of the processes to be simultaneously evaluated.

The focus for degradation in cell performance in our tests seems to be through $\mathrm{TiO}_{2}$ photocatalysed attack on the electrolyte leading to consumption of the triiodide in the electrolyte. This seems to come from an initial exposure of $\mathrm{TiO}_{2}$ surfaces which is evidenced by a reduction in $R_{\mathrm{BR}}$. The fall in $R_{\mathrm{BR}}$ coincides with the onset of discolouration of the electrolyte and is far more rapid in cells under load. This indicates that, at open circuit, electrons injected into the $\mathrm{TiO}_{2}$ by the dye are able to quench photogenerated holes as there is no external transport mechanism. When an external circuit is present, fewer $\mathrm{TiO}_{2}$ electron-hole pair recombinations occur, leading to an increase in hole concentration and an increase in the rate of $\mathrm{I}_{3}{ }^{-}$consumption and therefore cell degradation. In addition, removal of bandgap photons in the range $<400 \mathrm{~nm}$ stops the degradation of the electrolyte from occurring. One reaction that could occur from the oxidative 
hole is the conversion of $\mathrm{I}^{-}$to $\mathrm{I}_{3}{ }^{-}$resulting in increased triiodide production and therefore an increase absorbance at $450 \mathrm{~nm}$. Since this is not the case, then it could be possible that the triiodide is oxidised to iodate. Work is continuing in order to determine whether or not this is the case and to establish if iodate is the reaction product and the nature of the oxygen source (water or oxygen in the electrolyte or directly from $\mathrm{OH}$ moieties on the $\mathrm{TiO}_{2}$ surface).

It seems that in the timescale of our irradiations, at least the dye is not subject to degradation. Since it is the $\mathrm{TiO}_{2}$ photocatalysed oxidation that dominates, DSC stability can be improved as would be expected by including appropriate filters into the device to remove photons in the range of the bandgap of the $\mathrm{TiO}_{2}$. In addition, application of a reverse bias appears to regenerate depleted triiodide and restore cell performance of UV-photodegraded DSCs. Work is also continuing to establish whether a periodically applied reverse bias to DSCs under UV and visible light soaking conditions is an effective means of maintaining cell performance.

\section{Acknowledgment}

The authors would like to acknowledge support from the Engineering Physical Science Research Council (EP/ E035205), the ERDF, through the Low Carbon Research Institute, Tata Steel Europe, PV Accelerator, Shotton Works, Deeside, and SPECIFIC at the College of Engineering, Swansea University.

\section{References}

[1] M. Grätzel, "The advent of mesoscopic injection solar cells," Progress in Photovoltaics, vol. 14, no. 5, pp. 429-442, 2006.

[2] M. Grätzel and B. O’Regan, "A low-cost, high-efficiency solar cell based on dye-sensitized colloidal $\mathrm{TiO}_{2}$ films," Nature, vol. 353, no. 6346, pp. 737-740, 1991.

[3] M. K. Nazeeruddin, A. Kay, I. Rodicio et al., "Conversion of light to electricity by cis-X2bis (2,2' -bipyridyl-4,4' -dicarboxylate)ruthenium(II) charge-transfer sensitizers (X = Cl-, Br-, I-, $\mathrm{CN}-$, and $\mathrm{SCN}-$ ) on nanocrystalline $\mathrm{TiO}_{2}$ electrodes," Journal of the American Chemical Society, vol. 115, no. 14, pp. 63826390, 1993.

[4] J. Li, L. M. Peter, and R. Potter, "Photoelectrochemical response of $\mathrm{TiO}_{2}$ pigmented membranes," Journal of Applied Electrochemistry, vol. 14, no. 4, pp. 495-504, 1984.

[5] A. Mills, R. H. Davies, and D. Worsley, "Water purification by semiconductor photocatalysis," Chemical Society Reviews, vol. 22, no. 6, pp. 417-425, 1993.

[6] A. Wold, "Photocatalytic properties of titanium dioxide $\left(\mathrm{TiO}_{2}\right)$," Chemistry of Materials, vol. 5, no. 3, pp. 280-283, 1993.

[7] D. F. Ollis, E. Pelizzetti, and N. Serpone, Photocatalysis: Fundamentals and Applications, John Wiley and Sons, New York, NY, USA, 1989.

[8] A. J. Robinson, J. R. Searle, and D. A. Worsley, "Novel flat panel reactor for monitoring photodegradation," Materials Science and Technology, vol. 20, no. 8, pp. 1041-1048, 2004.

[9] S. Liu, J. Yu, and M. Jaroniec, "Tunable photocatalytic selectivity of hollow $\mathrm{TiO}_{2}$ microspheres composed of anatase polyhedra with exposed 001 facets," Journal of the American Chemical Society, vol. 132, no. 34, pp. 11914-11916, 2010.
[10] Q. Xiang, J. Yu, and M. Jaroniec, "Tunable photocatalytic selectivity of $\mathrm{TiO}_{2}$ films consisted of flower-like microspheres with exposed 001 facets," Chemical Communications, vol. 47, no. 15, pp. 4532-4534, 2011.

[11] H. Matsui, K. Okada, T. Kitamura, and N. Tanabe, “Thermal stability of dye-sensitized solar cells with current collecting grid," Solar Energy Materials and Solar Cells, vol. 93, no. 6-7, pp. 1110-1115, 2009.

[12] M. Grätzel, "Photovoltaic performance and long-term stability of dye-sensitized meosocopic solar cells," Comptes Rendus Chimie, vol. 9, no. 5-6, pp. 578-583, 2006.

[13] P. M. Sommeling, M. Späth, H. J. P. Smit, N. J. Bakker, and J. M. Kroon, "Long-term stability testing of dye-sensitized solar cells," Journal of Photochemistry and Photobiology A, vol. 164, no. 1-3, pp. 137-144, 2004.

[14] A. Hinsch, J. M. Kroon, R. Kern et al., "Long-term stability of dye-sensitised solar cells," Progress in Photovoltaics, vol. 9, no. 6, pp. 425-438, 2001.

[15] R. Harikisun and H. Desilvestro, "Long-term stability of dye solar cells," Solar Energy, vol. 85, no. 6, pp. 1179-1188, 2011.

[16] N. Kato, K. Higuchi, H. Tanaka, J. Nakajima, T. Sano, and T. Toyoda, "Improvement in long-term stability of dye-sensitized solar cell for outdoor use," Solar Energy Materials and Solar Cells, vol. 95, no. 1, pp. 301-305, 2011.

[17] H. Tributsch, A. Barkschat, T. Moehl, and B. MacHt, "The function of $\mathrm{TiO}_{2}$ with respect to sensitizer stability in nanocrystalline dye solar cells," International Journal of Photoenergy, vol. 2008, Article ID 814951, 13 pages, 2008.

[18] N. Kato, Y. Takeda, K. Higuchi et al., "Degradation analysis of dye-sensitized solar cell module after long-term stability test under outdoor working condition," Solar Energy Materials and Solar Cells, vol. 93, no. 6-7, pp. 893-897, 2009.

[19] M. Toivola, J. Halme, L. Peltokorpi, and P. Lund, "Investigation of temperature and aging effects in nanostructured dye solar cells studied by electrochemical impedance spectroscopy," International Journal of Photoenergy, vol. 2009, Article ID 786429, 15 pages, 2009.

[20] M. I. Asghar, K. Miettunen, J. Halme et al., "Review of stability for advanced dye solar cells," Energy and Environmental Science, vol. 3, no. 4, pp. 418-426, 2010.

[21] A. Hauch and A. Georg, "Diffusion in the electrolyte and charge-transfer reaction at the platinum electrode in dyesensitized solar cells," Electrochimica Acta, vol. 46, no. 22, pp. 3457-3466, 2001.

[22] B. Macht, M. Turrión, A. Barkschat, P. Salvador, K. Ellmer, and H. Tributsch, "Patterns of efficiency and degradation in dye sensitization solar cells measured with imaging techniques," Solar Energy Materials and Solar Cells, vol. 73, no. 2, pp. 163173, 2002.

[23] H. Pettersson and T. Gruszecki, "Long-term stability of low-power dye-sensitised solar cells prepared by industrial methods," Solar Energy Materials and Solar Cells, vol. 70, no. 2, pp. 203-212, 2001.

[24] K. Tennakone, G. R. R. A. Kumara, I. R. M. Kottegoda, K. G. U. Wijayantha, and V. P. S. Perera, "A solid-state photovoltaic cell sensitized with a ruthenium bipyridyl complex," Journal of Physics D, vol. 31, no. 12, pp. 1492-1496, 1998.

[25] H. Desilvestro, M. Bertoz, S. Tulloch, and G. Tulloch, "Packaging, scale-up and commercialization of dye solar cells," in DyeSensitized Solar Cells, K. Kalyanasundaram, Ed., EPFL Press, Lausanne, Switzerland, 2010.

[26] ASTM International ASTM G173-03. Standard Tables for Reference Solar Spectral Irradiances: Direct Normal and Hemispherical on $37^{\circ}$ Tilted Surface, 2008. 
[27] M. Grätzel, "Perspectives for dye-sensitized nanocrystalline solar cells," Progress in Photovoltaics, vol. 8, no. 1, pp. 171-185, 2000.

[28] S. Ferrere and B. A. Gregg, "Large increases in photocurrents and solar conversion efficiencies by UV illumination of dye sensitized solar cells," Journal of Physical Chemistry B, vol. 105, no. 32, pp. 7602-7605, 2001. 


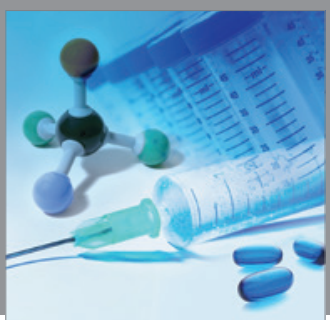

International Journal of

Medicinal Chemistry

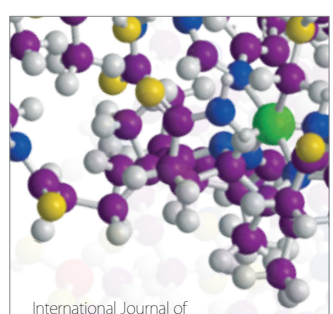

Carbohydrate Chemistry

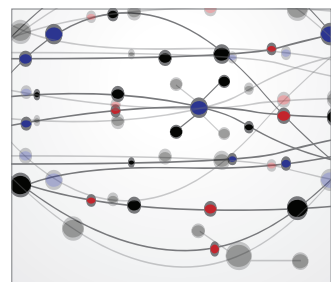

The Scientific World Journal
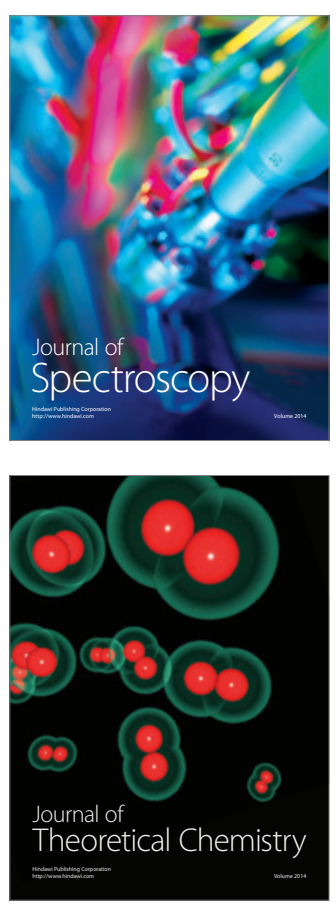
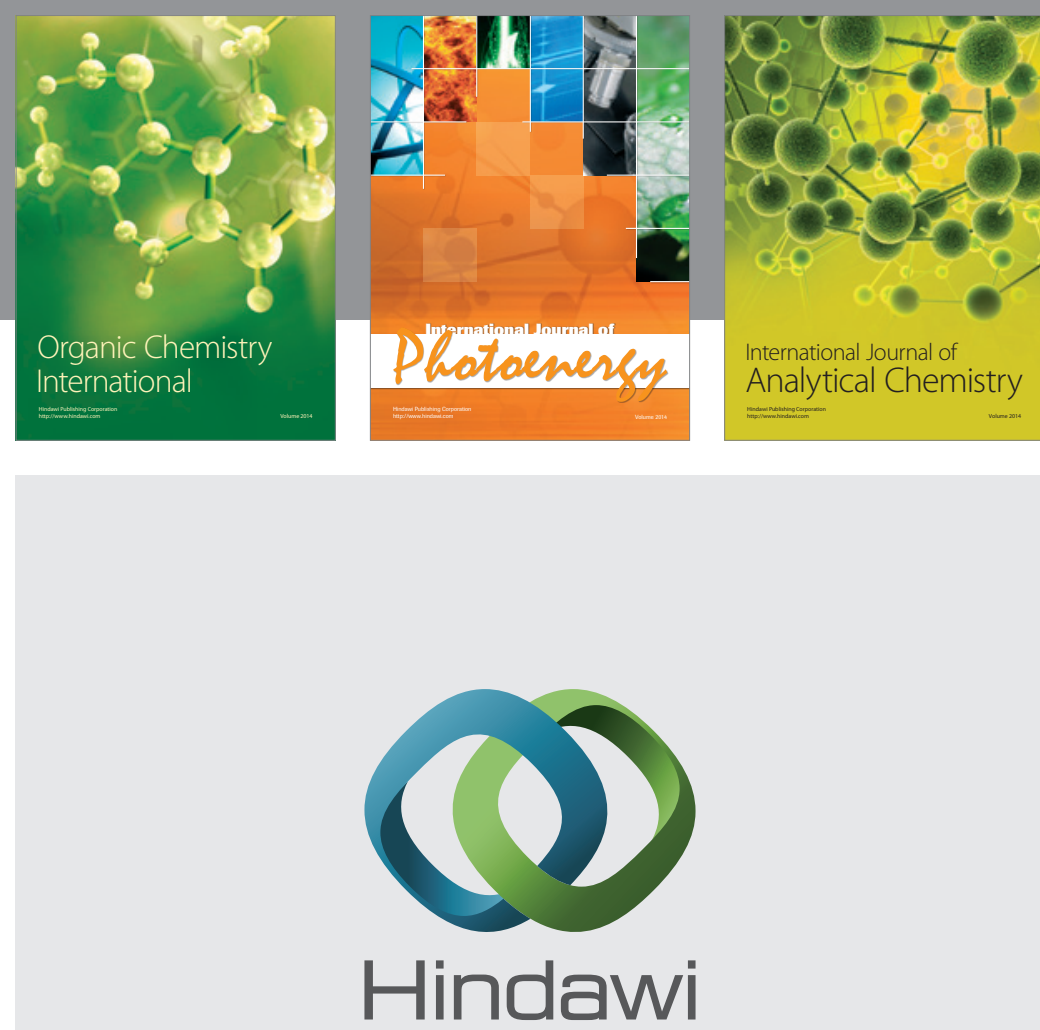

Submit your manuscripts at

http://www.hindawi.com
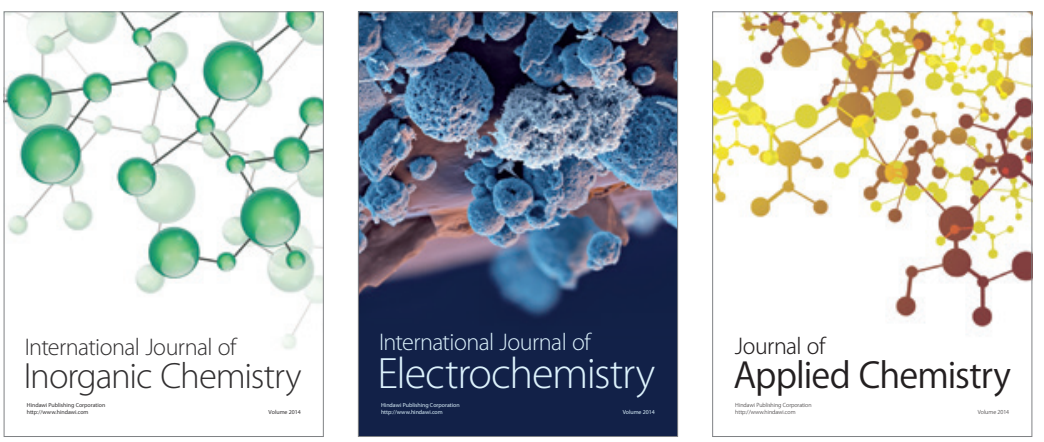

Journal of

Applied Chemistry
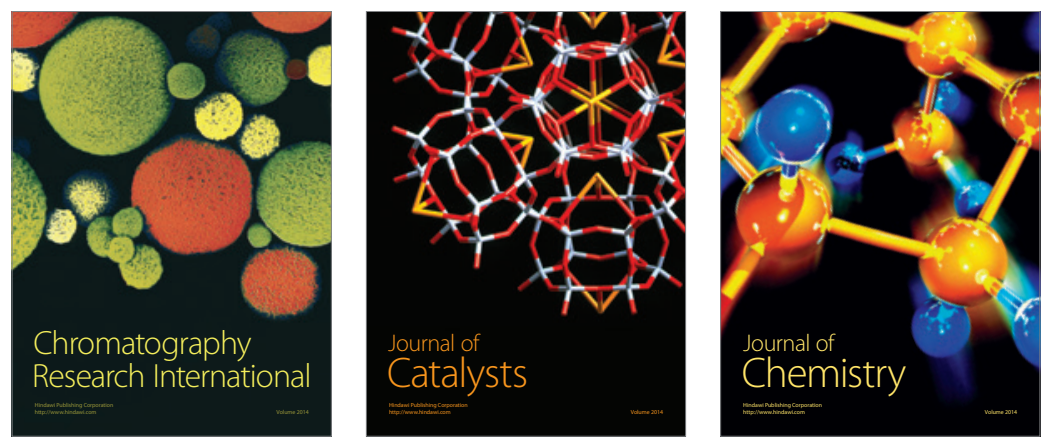
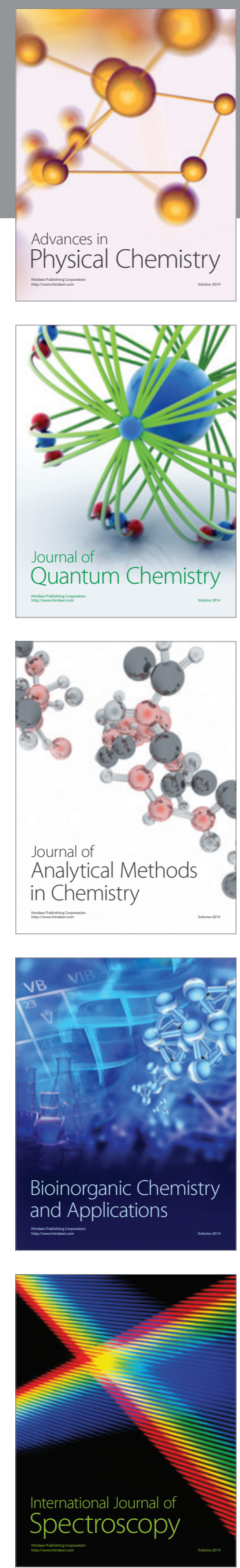